\title{
CONTRIBUIÇÃO DO HÁBITO DE LEITURA DOS DISCENTES DO CURSO DE CIÊNCIAS CONTÁBEIS PARA O DESENVOLVIMENTO DE COMPETENCIAS PROFISSIONAIS
}

\author{
CONTRIBUTION OF THE READING HABIT OF ACCOUNTING SCIENCE \\ STUDENTS IN THE DEVELOPMENT OF PROFESSIONAL SKILLS
}

\author{
DEBORAH MARIA DE SOUSA NASCIMENTO \\ Universidade Federal do Ceará. Endereço: Avenida da Universidade, $n^{\circ} 2431$ \\ | Benfica | 60020-180| Fortaleza/CE | Brasil. \\ (10) http://orcid.org/0000-0002-2439-1566 \\ maria_deby@yahoo.com.br
}

\author{
EDITINETE ANDRE DA ROCHA GARCIA \\ Universidade Federal do Ceará. Endereço: Avenida da Universidade, $n^{\circ} 2431$ \\ | Benfica | 60020-180| Fortaleza/CE | Brasil. \\ (1) http://orcid.org/0000-0002-5782-9579 \\ editinete@hotmail.com
}

\author{
ANTONIO RODRIGUES ALBUQUERQUE FILHO \\ Universidade Federal do Ceará. Endereço: Avenida da Universidade, $n^{\circ} 2431$ \\ | Benfica | 60020-180 | Fortaleza/CE | Brasil. \\ (D) http://orcid.org/0000-0003-2108-3979 \\ antoniofilhoufc@hotmail.com
}

\section{RESUMO}

Este estudo objetivou identificar a contribuição do hábito de leitura dos estudantes de ciências contábeis para a sua formação profissional como contadores a partir da aplicação do teste de Cloze (Taylor, 1953) e da escala de funções de leitura (Greaney \& Neuman, 1990). Assim, a pesquisa de caráter exploratório investiga, em uma instituição de ensino superior, se o hábito de leitura dos estudantes favorece a utilização de tal habilidade como instrumento para desenvolver competências profissionais do contador. A amostra é composta de 180 universitários do curso de Ciências Contábeis de uma instituição de ensino superior, obtida por acessibilidade. Na coleta de dados, foi aplicado questionário contendo a escala de funções da leitura, com as funções aprendizagem, utilidade, moralidade e estímulo, bem como um texto preparado segundo a técnica Cloze. As respostas foram consolidadas e analisadas à luz do que estabelece o Dicionário de Competência do Contador. A partir dos resultados da aplicação do teste de Cloze, verifica-se que os alunos apresentam dificuldades na compreensão textual. Em relação aos testes de função de leitura, os resultados demonstraram maior uso das funções aprendizagem e utilidade pelos universitários. Verificou-se que há ambiente propício para o desenvolvimento das competências 
do contador ligadas à aprendizagem e à utilidade por meio da leitura, porém as funções moralidade e estímulo precisam ser incentivadas de modo a superar as dificuldades de compreensão.

Palavras-chave: Funções da leitura. Compreensão da leitura. Competências do contador.

\begin{abstract}
This paper aims to identify the reading habit contribution of accounting students for their professional improvement as an accountant using Cloze test (Taylor, 1953) and reading functions scale (Greaney \& Neuman, 1990). The research is an exploratory investigation, applied at a university to verify if undergraduate students habit improves their professional skills. The sample is composed by 180 students from the Accounting Sciences course, and it was obtained by accessibility. For data collection, it was applied a questionnaire containing the reading function scale with the following functions: general learning; utility; morality; and stimulation, as well as a text prepared with Cloze technique. The answers were consolidated and analyzed applying the established by the Dicionário de Competencia do Contador. Based on the results of the Cloze test it was verified that the undergraduate students present difficulties in textual comprehension. Concerning the reading function tests, the results showed a better use of the Utility and General Learning functions. It reveals that there is a property environment for developing the Accountant skills related to the General Learning and Utility, through reading; however, Morality and Stimulation should be encouraged to overcome comprehension difficulties.
\end{abstract}

Keywords: Reading Functions. Reading Comprehension. Accountant Skills.

\title{
1 INTRODUÇÃO
}

A leitura é o principal meio de aprendizagem e aplicação prática de que o profissional contábil dispõe, uma vez que a atividade é regulamentada por grande quantidade de leis e normas. Dessa forma, para que o contador desempenhe as funções a si cometidas de maneira correta, é exigida a observância desses normativos. Tal fato se acentuou na última década, uma vez que o Brasil passou por uma reforma importante no seu sistema contábil, ao se inserir no contexto internacional de adoção de normas internacionais de Contabilidade. Essas mudanças foram implantadas em 2005, com a criação do Comitê de Pronunciamentos Contábeis (CPC).

$\mathrm{O}$ volume expressivo e as constantes modificações dos normativos a serem seguidos evidenciam a necessidade da leitura de que o profissional contador necessita para exercer o seu ofício, ao buscar-se manter atualizado no mercado de trabalho. Sendo assim, é essencial que tal prática seja incentivada e desenvolvida nos futuros profissionais, mesmo ainda na fase de graduação. Os alunos de Contabilidade devem sair da universidade como bons leitores, possuindo um hábito de leitura solidificado.

A leitura é indispensável na universidade, de maneira significativa. A relevância dessa prática em cursos de graduação e o diagnóstico do nível de leitura dos universitários, bem como de suas funções predominantes, foram alvo dos estudos de Oliveira (1996), Witter (1997) e Pires (2012), dentre outros. Os resultados desses estudos demonstram a importância e a influência da leitura na formação profissional dos estudantes, sendo imprescindível para o ensino-aprendizagem no ambiente universitário, e contribuindo para a formação de profissionais qualificados, de acordo com as especificidades de seu ofício.

Nessa perspectiva, considera-se essencial o diagnóstico da habilidade de leitura dos alunos e seu reflexo no desempenho de competências para seu desenvolvimento como profissional. Assim, conforme Silva (1992), ao situar-se no ato de ler, o leitor se conscientiza de que seu objetivo é a compreensão e a crítica, e não a simples memorização. Ao constatar o significado do 
texto, o leitor crítico desvenda a mensagem do autor e reage a ela com criticidade, fazendo questionamentos, posicionando-se perante a ideia transmitida, dando início ao seu cotejo. Após decodificar e refletir, procede-se à transformação, em que o leitor age sobre o conteúdo do conhecimento, recriando-o. Ao final do processo, a leitura crítica resulta na elaboração de um novo texto atribuído ao leitor.

De acordo com Cardoso (2006) as competências do contador são interligadas aos conhecimentos que o profissional da área deve apresentar. Nessa linha, percebe-se a importância da compreensão da leitura, na medida em que os conceitos e normas devem ser atendidos em sua essência para serem colocados em prática corretamente.

Em razão da realidade exigida para o profissional de Contabilidade, e considerando a influência da leitura no decurso de formação profissional, este texto exprime a seguinte questão de pesquisa: qual a contribuição do hábito de leitura dos discentes do curso de Ciências Contábeis de uma instituição de ensino superior para o desenvolvimento de competências profissionais do contador?

Esta investigação difere das demais da área de leitura pelo fato de analisar a temática relacionando-a com as competências específicas que o profissional de contabilidade deve obter, buscando estabelecer ligação das funções da leitura e da compreensão com a formação de tais habilidades.

Com suporte na análise das funções da leitura, aprendizagem, utilidade, moralidade e estímulo propostas por Greaney e Neuman (1990), estabeleceu-se a relação com as dez competências descritas no Dicionário de Competências do Contador, evidenciadas por Cardoso (2006). Como ponderado por Greaney e Neuman (1990) tais funções, através da prática de leitura, agregam características que permitem desenvolver o conhecimento (aprendizagem), estimular a imaginação (estímulo) e a formação ética e moral (moralidade), além de aprimorar a linguagem oral e escrita (utilidade) do aluno. Isso pode ocasionar a formação de competências (Cardoso, 2006) e habilidades que possibilitem adequado conhecimento para ingressar no mercado de trabalho.

Assim, o estudo é desenvolvido com o objetivo de identificar a contribuição do hábito de leitura dos estudantes de Ciências Contábeis para a sua formação profissional, a partir da aplicação do teste de Cloze e da escala de funções de leitura proposta por Greany e Neuman (1990).

Para responder a questão de pesquisa e atingir o objetivo geral, o estudo será desenvolvido para: (i) identificar as habilidades e conhecimentos a serem desenvolvidas no curso de ciências contábeis a partir da leitura para o desenvolvimento profissional; (ii) identificar o perfil de leitura dos estudantes do curso de Ciências Contábeis de uma instituição de ensino superior; e (iii) apresentar diagnóstico sobre o hábito de leitura dos discentes do curso de Ciências Contábeis de uma instituição de ensino superior, relacionando-o à sua formação como contador.

\section{FUNDAMENTAÇÃO TEÓRICA}

\subsection{A leitura, suas funções e a compreensão}

Por viver em sociedade, o ser humano sente a necessidade de se expressar, e esse estímulo o levou a desenvolver quatro habilidades básicas: falar, ouvir, ler e escrever. Assim, a linguagem é utilizada como forma de comunicação em um sistema de representações e possibilidades (Chaguri, Barbosa, Arouca \& Wuo, 1997).

O desenvolvimento da comunicação humana por meio da escrita fez da leitura um dos principais meios pelos quais o homem adquire conhecimento sobre o mundo, conhecendo os povos, suas conquistas e descobertas, os pensamentos e sentimentos das pessoas, dentre outros. 
Assim, a leitura tem importância fundamental nesse processo (Centofanti, Ferreira \& Tedesco, 1997).

O ato de ler, porém, não pode ser encarado apenas como simples decodificação de signos. Como ensina Freire (2017, p. 11), "A leitura do mundo precede a leitura da palavra, daí a posterior leitura desta não possa prescindir da continuidade da leitura daquele”. Para o autor, ler passa a implicar, desde então, a percepção das relações entre texto e contexto, não havendo significado na leitura sem que essa esteja inserida numa sociedade.

A leitura é evidenciada nos variados níveis da educação, iniciando-se no período da alfabetização, com a aprendizagem dos significados das palavras escritas, e prosseguindo com o contato literário e bibliográfico durante toda a vida acadêmica (Silva, 2011). Ao tratar das relações entre leitura e universidade, Witter (1997) destaca a ideia de que cada elemento possui isoladamente sua complexidade. Sendo assim, a relação entre as duas variáveis não poderia deixar de ser igualmente complexa. $\mathrm{Na}$ intelecção da autora, a leitura é um elemento fundamental para o processo de ensino-aprendizagem no ambiente universitário.

É de se esperar que, para ingressar na universidade, o aluno já tenha adquirido a habilidade de leitura e compreensão de textos, pois dele é exigido que, durante o curso, exerça criatividade, independência, capacidade de buscar opções, formular hipóteses e compreender de maneira crítica a leitura em foco (Tourinho, 2011).

Estudos demonstram, entretanto, que o aluno de nível superior expressa dificuldades na compreensão de textos, fato sugestivo de que essa habilidade não tenha sido adquirida adequadamente em sua formação anterior. Essa deficiência pode ocasionar a conclusão do curso universitário pelos discentes, sem que possuam adequado conhecimento técnico para ingressar no mercado de trabalho. Esses trabalhos defendem programas de remediação das deficiências de leitura dos universitários (Freitag, Sarmento, Costa \& Santos, 2014; Oliveira \& Oliveira, 2007; Santos, Suehiro \& Oliveira, 2004; Witter, 1997).

Ao deparar-se com a complexidade da análise científica dos problemas de ensinoaprendizagem por meio da leitura, torna-se necessário prestar atenção especial aos hábitos de leitura dos estudantes universitários, bem como às dificuldades enfrentadas por eles na compreensão dos textos (Pinto, Alvarenga \& Kock, 1997).

Paralelamente aos trabalhos sobre compreensão, existem os estudos sobre os motivos para ler. Greaney e Neuman (1990), por meio de perspectiva transcultural, definiram dez funções da leitura: aprendizagem, lazer, fuga, estímulo, preencher tempo, alvos sociais definidos, moralidade, autorrespeito, flexibilidade e utilidade. A partir de sua pesquisa, foi criada a Escala de Funções da Leitura, questionário que consiste em 50 afirmativas, cinco para cada função, a partir do qual é possível identificar as funções predominantes no habito de leitura dos respondentes.

Ao identificar e estudar essas funções na universidade, tem-se melhor entendimento dos estudantes na condição de leitores, proporcionando oportunidades de remediar e desenvolver a prática da leitura, tendo como consequência a melhora no desempenho acadêmico dos alunos por meio do aprimoramento do ensino-aprendizagem (Centofanti et al., 1997).

Dentre as funções indicadas por Greaney e Neuman (1990), foram utilizadas na pesquisa aprendizagem, estímulo, moralidade e utilidade, consideradas nesse estudo como relacionadas diretamente ao desenvolvimento de competências profissionais do contador, conforme demonstrado no tópico seguinte. A aprendizagem valoriza a obtenção e desenvolvimento do conhecimento; o estímulo propicia a imaginação e a fantasia; a moralidade proporciona a formação ética e moral; e a utilidade confere valor ao aprimoramento da linguagem oral e escrita (Greaney \& Neuman, 1990). 


\subsection{As competências profissionais, as habilidades do contador e a leitura}

O termo competência tem origem latina, e vem da palavra competentia, que significa "a qualidade de quem é capaz de apreciar e resolver determinado assunto, de fazer algo de maneira capaz, com habilidade, aptidão e idoneidade" (Cardoso \& Riccio, 2010, p. 355). A palavra é utilizada no senso comum com o sentido de qualificação para realizar determinada tarefa, e o seu antônimo carrega um sentido pejorativo no contexto do ambiente de trabalho (Fleury \& Fleury, 2001).

No universo científico, as discussões sobre competências tiveram início nos Estados Unidos, por intermédio de McClelland (1973), e ocorreram entre psicólogos e administradores (Fleury \& Fleury, 2001). Autor aborda de maneira crítica os testes de inteligência utilizados na época para selecionar candidatos a vagas de emprego e estudo nas universidades, e sugere uma mudança no critério de seleção, para que as competências do candidato venham a ser consideradas (McClelland, 1973).

Diversos estudiosos abordaram o tema, mas ainda não se chegou a um consenso sobre seu conceito e o problema não pode dar-se como resolvido, tratando-se de um construto em formação (Cardoso \& Riccio, 2010).

A esse respeito, Ramirez (2003) esclarece que não há como separar os saberes (saber ser, saber fazer e saber agir), nem o intelecto das nossas vontades e capacidades físicas e motoras, pois o ser humano é integrado. Dessa forma, o autor considera a competência como a junção da tríade: conhecimento, habilidades e atitudes.

Por conhecimento, entende-se "o conjunto de fatos, informações, princípios e conceitos importantes para resolver pontos, questões e problemas relacionados ao trabalho" (Cardoso, 2006, p. 96). Habilidade é "a capacidade de saber fazer alguma coisa através de ações ordenadas e com finalidades dirigidas para a realização de um objetivo" (Ramirez, 2003, p. 21). Já as atitudes são divisadas como iniciativas pessoais (Cardoso, Souza \& Almeida, 2006). A junção dos três conceitos resulta na competência.

As competências citadas pelos estudiosos em abordagem do tema, atreladas aos seus conceitos, foram compiladas e transformadas no Dicionário de Competências do Contador por Cardoso (2006), baseado no modelo de dicionário de competências profissionais proposto por Spencer e Spencer (1993).

O Dicionário é composto por 18 competências classificadas em capacidades, habilidades, conhecimentos e outras características. Em capacidades, encontram-se a competência analítica e de comunicação; como habilidades, estratégica, informática, negociação, ouvir eficazmente, atendimento e relacionamento externo; os conhecimentos são distribuídos em ferramentas de controle, legal, contabilidade e finanças, planejamento, técnicas de gestão e gestão da informação; e autocontrole, empreendedor, integridades e confiança e trabalho em equipe foram agrupados em outras características (Cardoso, 2006).

A seguir destaca-se a relação das competências descritas no Dicionário de Competências do Contador, de acordo com Cardoso (2006), conforme a Tabela 1.

Tabela 1

\section{Competências do contador}

\begin{tabular}{c|l}
\hline Competência & \multicolumn{1}{c}{ Conceito } \\
\hline Analítica & $\begin{array}{l}\text { Sabe analisar as partes de um problema ou situação, estabelecendo suas relações para } \\
\text { formular diversas soluções e o valor de cada uma. } \\
\text { Moramed e Lashine (2003) e AICPA (1999) }\end{array}$ \\
\hline Comunicação & $\begin{array}{l}\text { Estabelece sintonia nas comunicações com pessoas ou grupos, entendendo } \\
\text { mensagens e sendo entendido. Demonstra boa articulação ao comunicar ideias por } \\
\text { escrito e verbalmente. } \\
\text { Boyatzis, Stubbs e Taylor (2002), IFAC (2003) e Abdolmohammadi, Searson e } \\
\text { Shanteau (2004) }\end{array}$ \\
\hline
\end{tabular}




\begin{tabular}{|c|c|}
\hline Ouvir eficazmente & $\begin{array}{l}\text { Desenvolve diálogos interativos com as pessoas, pergunta por mais detalhes sobre os } \\
\text { assuntos, avalia mensagens e fornece feedback. } \\
\text { Morgan (1997) e } A A A \text { - Francis, Mulder e Stark (1995) }\end{array}$ \\
\hline Integridade e confiança & $\begin{array}{l}\text { Tem integridade exprime positivamente seus valores e crenças pessoais de maneira } \\
\text { consistente com os padrões éticos de sua empresa. Inspira confiança pelo } \\
\text { cumprimento dos compromissos assumidos. } \\
\text { Bower (1957) }\end{array}$ \\
\hline Planejamento & $\begin{array}{l}\text { Estuda e aplica conceitos de planejamento e acompanhamento estratégico, } \\
\text { operacional e financeiro auxiliando a alta administração no alcance dos seus } \\
\text { objetivos. } \\
\text { Hardern (1995) e Needles, Cascini, Krylova e Moustafa (2001) }\end{array}$ \\
\hline Empreendedor & $\begin{array}{l}\text { Desenvolve soluções criativas aos problemas da empresa e dos clientes; procura } \\
\text { inovar diante das restrições da empresa. Assume riscos calculados. } \\
\text { Spencer e Spencer (1993), Handern (1995) e Laurie (1995) }\end{array}$ \\
\hline Ferramentas de controle & $\begin{array}{l}\text { Conhece e utiliza as ferramentas de controle e gestão, como orçamento, controle } \\
\text { interno, custos, fluxo de caixa, entre outros. } \\
\text { Henning e Moseley (1970) e Siegel e Sorensen (1999) }\end{array}$ \\
\hline Legal & $\begin{array}{l}\text { Conhece e acompanha as tarefas obrigatórias como: planejamento tributário e } \\
\text { atendimento às exigências fiscais. } \\
\text { Kester (1928) e Henning e Moseley (1970) }\end{array}$ \\
\hline Contabilidade e finanças & $\begin{array}{l}\text { Domina e interpreta os conceitos relacionados à área de contabilidade e finanças } \\
\text { empresariais atendendo a interesses dos usuários internos e externos desta informação } \\
\text { e das normas vigentes no ambiente nacional e internacional. } \\
\text { Bower (1975) e Henning e Moseley (1970) }\end{array}$ \\
\hline Técnicas de gestão & $\begin{array}{l}\text { Demonstra estar atualizado com as técnicas, dados e novos conhecimentos por meio } \\
\text { de leitura, cursos, viagens, congressos etc. } \\
\text { Laurie (1995) e Siegel e Sorensen (1999) }\end{array}$ \\
\hline
\end{tabular}

Fonte: Cardoso (2006).

Conforme descrito na Tabela 1, entre as competências do contador reunidas por Cardoso (2006), é possível identificar as ligadas a conhecimentos que esse profissional deve possuir: planejamento, ferramentas de controle, contabilidade e finanças, legal e técnicas de gestão. A competência "planejamento" exige que o contador estude e aplique conceitos ligados a essa área. "Ferramentas de controle" preza pelo seu conhecimento e utilização. A competência "legal" requer conhecimento e acompanhamento das obrigações fiscais, bem como das constantes atualizações na legislação que permeiam a profissão. "Contabilidade e finanças" pede o domínio e interpretação dos conceitos relacionados à área, buscando o atendimento das normas nacionais e internacionais. Já "técnicas de gestão" requer atualização quanto às técnicas, dados e novos conhecimentos - o autor cita a leitura como meio de alcance dessa exigência (Cardoso, 2006).

Dentre as competências exigidas para o contador, figuram ainda "comunicação" e "ouvir eficazmente". Conforme a Tabela 1, a primeira é definida como capacidade de entender mensagens e ser entendido, fazer-se entender por escrito e verbalmente. Já a segunda é definida como habilidade de avaliar mensagens e desenvolver diálogos interativos (Cardoso, 2006). Na competência "analítica", é requerida a capacidade de saber analisar as partes de um problema ou situação. "Integridade e confiança", por sua vez, retrata o fato de que o profissional deve exprimir valores e crenças em sintonia com os padrões éticos da empresa ao passo que a competência "empreendedor" requer o desenvolvimento de soluções criativas e a inovação diante das restrições.

$\mathrm{Na}$ Tabela 2, denota-se a associação das funções da leitura propostas por Greaney e Neuman (1990) com as competências descritas no Dicionário de Competências do Contador, evidenciadas por Cardoso (2006). 
Tabela 2

\section{Relação das funções de leitura com as competências do contador}

\begin{tabular}{|c|c|}
\hline Funções de leitura & Competência \\
\hline $\begin{array}{l}\text { Aprendizagem - valoriza a aquisição e o desenvolvimento de conhecimentos por parte do } \\
\text { leitor (Greaney \& Neuman, 1990). Pires (2012) argumenta que a leitura na universidade } \\
\text { é algo indispensável para desenvolver profissionais qualificados por ser associada à } \\
\text { obtenção de conhecimento. O autor considera ainda que desenvolver esse hábito é } \\
\text { essencial aos estudantes na qualidade de futuros profissionais, pois necessitam } \\
\text { acompanhar os conhecimentos constantemente produzidos ligados a sua área de atuação } \\
\text { profissional. }\end{array}$ & $\begin{array}{l}\text { Planejamento, } \\
\text { ferramentas de controle, } \\
\text { contabilidade e finanças, } \\
\text { legal, técnicas de gestão }\end{array}$ \\
\hline $\begin{array}{l}\text { Utilidade - por meio dela o leitor demonstra interesse pelo aprimoramento da linguagem } \\
\text { oral e escrita (Greaney \& Neuman, 1990). É necessário que os estudantes saibam } \\
\text { expressar seus sentimentos, pensamentos e ideias para que tenham sucesso profissional, } \\
\text { e essa formação deve ser pretensão da universidade (Centofanti et al., 1997). As autoras } \\
\text { consideram, ainda, que a habilidade de expressar-se pode ser adquirida por meio da } \\
\text { prática da leitura e da escrita ao longo da formação acadêmica. }\end{array}$ & $\begin{array}{l}\text { Comunicação, ouvir } \\
\text { eficazmente }\end{array}$ \\
\hline $\begin{array}{l}\text { Moralidade - é a função cuja prática valoriza a formação moral e ética (Greaney \& } \\
\text { Neuman, 1990). Por meio da leitura, o universitário adquire padrões de comportamento e } \\
\text { incorpora valores que serão úteis, conferindo segurança na tomada de decisão, } \\
\text { argumentações e posicionamentos em sua vida pessoal e profissional (Pinto et al., 1997). } \\
\text { A leitura técnico-científica é necessária para o desempenho laboral, mas o estudante, } \\
\text { como cidadão, precisa dedicar-se a leituras de outras áreas de conhecimento para } \\
\text { enriquecimento pessoal, e a universidade não pode se abster desse fato (Witter, 1997). }\end{array}$ & Integridade e confiança \\
\hline $\begin{array}{l}\text { Estímulo - propicia imaginação e fantasia (Greaney \& Neuman, 1990). Segundo } \\
\text { Arrigucci (1994), "A experiência da leitura tem, de fato, . . essa energia de acender a } \\
\text { imaginação, despertando sua capacidade transformadora, seu poder de fogo de ligar } \\
\text { inusitadamente em novas unidades o simplesmente dado: abertura para o que poderia ser". } \\
\text { Durante a leitura, o consulente relaciona a fantasia que está no universo dos livros com a } \\
\text { realidade de seu meio social, o que enseja a sobreposição da criatividade, imaginação e } \\
\text { raciocínio em um palco de possibilidades (Brito, 2010). Ao falar de criatividade, Valentim } \\
\text { (2008, p. 4) a descreve como "um processo cognitivo, individual ou coletivo, que gera } \\
\text { ideias e perspectivas originais para uma determinada questão problemática ou não". Para } \\
\text { a autora, a implantação da ideia criativa tem como resultado a inovação. }\end{array}$ & $\begin{array}{l}\text { Analítica, } \\
\text { Empreendedor }\end{array}$ \\
\hline
\end{tabular}
Fonte: Elaborada pelos autores (2018).

Por meio da Tabela 2, infere-se que, por conter verbos como estudar, conhecer e dominar e ainda se referir diretamente a conceitos e normas em sua definição, as competências "planejamento", "ferramentas de controle", "contabilidade e finanças", "legal" e "técnicas de gestão" demonstram possuir afinidade com a função da leitura relacionada à função aprendizagem. A valoração da leitura com a função de adquirir conhecimentos torna propício o desenvolvimento das competências supracitadas.

Ademais, ao ter a leitura com a função de utilidade, interessando-se em aprimorar a linguagem oral e escrita, o estudante possibilita o desenvolvimento das competências que exigem tal aprimoramento, além de melhorar sua forma de expressar-se de maneira eficaz. Depreende-se ainda, por meio da Tabela 2, que o contador deve agir com ética ao exercer a profissão, competência cujo desenvolvimento é favorecido pela leitura voltada para a moralidade, na medida em que a formação ética é valorizada pelo aluno leitor e ele se torna entendedor de suas obrigações morais do campo profissional. Além disso, na leitura como função de estímulo, o aluno leitor torna propícia a aquisição das competências relacionadas à criatividade, sinalizando uma correlação dessa função com a competência "analítica" e "empreendedor".

De forma geral, para que o hábito de leitura atinja a função a que se propõe é necessário que o texto lido seja compreendido em sua totalidade. De nada servirá uma leitura com o objetivo de aprendizado, se o leitor não compreender plenamente a mensagem veiculada pelo autor por meio do texto. O mesmo vale para as demais funções da leitura. "Formar leitores críticos, com habilidades argumentativas e capacidade para resolução de problemas, deve ser um dos objetivos 
da maioria dos educadores. Não basta ler, há que se posicionar perante o que se lê." (Centofanti et al., 1997, p. 37).

Portanto, no que tange às competências do futuro profissional de contabilidade relacionadas ao conhecimento, percebe-se a importância da compreensão da leitura, na medida em que os conceitos e normas devem ser entendidos em sua essência para serem postos em prática corretamente. Cabe salientar que a não observância das normas legais ou sua aplicação equivocada pode resultar em prejuízo para a empresa, tanto financeiro, em decorrência de multas fiscais, quanto da confiabilidade das demonstrações contábeis, causado por distorções, podendo impactar erroneamente na tomada de decisão dos usuários da informação.

\section{METODOLOGIA}

Considerando o objetivo a que se propõe, a pesquisa foi classificada como exploratória e descritiva. Beuren e Raupp (2012) exprimem a ideia de que o estudo exploratório contribui para esclarecer questões abordadas de maneira superficial, aprofundando aspectos ainda não privilegiados em dado assunto. Gil (2010) ensina que a pesquisa exploratória proporciona maior conhecimento sobre o problema, com o objetivo de torná-lo mais explícito ou formular hipóteses a seu respeito. No que se refere à pesquisa descritiva, Gil (2012) leciona que seu principal objetivo é descrever características de determinada população.

Quanto à abordagem do problema, a pesquisa se classifica como quantitativa. Richardson (2012) acentua que a pesquisa quantitativa se caracteriza pelo emprego da quantificação, tanto nas modalidades de coleta de informações quanto no tratamento destas através de técnicas estatísticas, desde as mais simples às mais complexas, como testes de médias, análise de regressão etc. Assim, para este estudo, utilizou-se estatística descritiva e teste de médias (teste de Kruskal-Wallis).

Quanto aos procedimentos, utilizam-se pesquisa bibliográfica e survey. Martins e Theóphilo (2009) defendem que a primeira é necessária em todas as buscas científicas e, conforme Beuren e Raupp (2012), é por meio dela que se toma conhecimento sobre a produção científica produzida a respeito do tema, abrindo espaço para uma nova leitura, ao reunir diversas publicações isoladas. No que se refere à survey, Gil (2012) acentua que sua característica é a interrogação direta do grupo cujo comportamento se almeja conhecer e que é apropriada para estudos descritivos.

Os dados foram coletados a partir da técnica de questionário, de tamanho médio, o qual foi composto por duas dimensões e aplicado junto aos alunos de uma instituição de ensino superior situada no município de Fortaleza, CE. A primeira dimensão é baseada na Escala de Funções de Leitura, desenvolvida por Greaney e Neuman (1990), trazida e adaptada por Witter (1996). Das dez funções da escala, foram utilizadas na pesquisa as seguintes: aprendizagem, estímulo, moralidade e utilidade. Sendo assim, dos 50 itens do questionário, apenas 20 foram utilizados, e os itens da escala foram renumerados. Em cada função, delinearam-se cinco afirmativas, considerando as seguintes possibilidades e atribuição de pontuação: muito (3), mais ou menos (2), pouco (1) ou nada (0). Dessa forma, cada função poderá atingir até 15 pontos e o questionário completo poderá chegar ao máximo de 60 pontos por aluno.

A segunda dimensão do instrumento é um texto que visa analisar a compreensão da leitura dos estudantes, produzido segundo a técnica Cloze, criada por Taylor (1953). O teste de Cloze visa a avaliação da compreensão em leitura, sendo também utilizado para avaliar a legibilidade dos materiais escritos. O teste consiste em completar um texto no qual foram ocultadas palavras de maneira metódica, omitindo-se a quinta palavra sucessivas vezes. São deixadas lacunas de tamanho proporcional aos termos omitidos, e a primeira e a última frase do texto são preservadas na sua integridade. Desse modo, as palavras ocultadas são desvendadas pelo respondente a partir da leitura e compreensão do seu contexto. Assim, empregou-se um texto de aproximadamente 250 vocábulos do qual se omitiram todos os quintos vocábulos substituindo-os por um traço de tamanho proporcional ao da palavra omitida. 
O texto escolhido foi utilizado no Exame de Suficiência, edição 2014.2, e trata-se de um trecho de "Pequenos choques: a Bandejinha", de João Ubaldo Ribeiro (2011). A escolha por um texto literário em vez de um técnico da área contábil se deu pelo exposto por Centofanti et al. (1997), que aconselharam diversificar o material lido, despertando o interesse do aluno pela leitura. Além disso, deu-se também pelo fato de o estudo não considerar distinções entre os semestres, visto que se presume que alunos de semestres mais avançados possuem maior familiaridade com os termos técnicos da área contábil em relação aos de semestres mais recentes (Beck \& Rausch, 2015). Outrossim, conforme Alves (2005), o ato de ler depende do conhecimento prévio e do estabelecimento de ligações intertextuais que permitem uma leitura significativa, que, por conseguinte, contribui com o acúmulo de informações utilizado para uma prática profissional eficiente (Masetto, 2003).

A correção empregada foi a literal, que considerou como acerto o preenchimento exato da palavra omitida. Atribuiu-se 1 ponto para os acertos e 0 para os erros, portanto a pontuação poderia variar de 0 a 46 pontos. Em seguida, foi realizada uma análise por meio do teste de diferenças de médias de Kruskal-Wallis com intuito verificar diferenças entre vários grupos independentes, admitindo-se a não normalidade da variável de comparação entre os agrupamentos confrontados. Assim, buscou-se verificar se existiam diferenças significativas na compreensão dos alunos, medida pelo teste de Cloze com relação aos períodos anuais em que se encontravam.

O procedimento permite observar as interações da mente do leitor com o texto escrito, que se estabelecem no número de vezes em que palavras do texto foram sistematicamente omitidas. As lacunas do texto passam a constituir espaços de observação direta de compreensão que relacionam as experiências do mundo e da linguagem armazenadas na memória do leitor com as respostas semânticas e sintáticas obtidas no contexto para formar o significado. A técnica é aplicada com frequência pela comunidade científica, por ser de fácil aplicação, possuindo eficácia testada e comprovada quando avaliada a compreensão em leitura das pessoas pesquisadas. Seus resultados demonstraram correlações positivas entre a compreensão e o desempenho acadêmico, bem como a produção escrita entre universitários (Cunha \& Santos, 2006; Santos, Primi, Taxa \& Vendramini, 2002; Santos, Suehiro \& Oliveira, 2004).

Para o agrupamento das respostas do teste de Cloze, adotaram-se três critérios, estabelecidos por Bormuth (1968). O primeiro faz referência ao nível de frustração e diz respeito ao fato de o leitor não ter abstraído de forma adequada a informação lida (pontuação de até $44 \%$ de acertos). O segundo critério é o instrucional, compreensão apenas suficiente para o entendimento (de $44,1 \%$ a $57 \%$ de acertos). Por fim, o nível independente indica uma compreensão criativa, autônoma e fluente do texto (superiores a 57\% de acertos). Ao identificar em qual nível de leitura os estudantes de Contabilidade de uma instituição de ensino superior estão classificados por meio da compreensão textual, pretende-se investigar se seu hábito de leitura favorece a utilização da habilidade como instrumento para desenvolver as competências profissionais do contador.

\subsection{Definição da amostra}

O curso de Ciências Contábeis da instituição de ensino superior contou com um universo de 822 alunos nos turnos diurno e noturno. A amostra foi composta de 180 discentes de todos os semestres desse programa de graduação e foi coletada por acessibilidade (Gil, 2012). A escolha da amostra se deu por disponibilidade de turmas para aplicação do questionário, junto aos professores do curso.

\section{RESULTADOS}

Para efeitos de análise da relação entre o hábito de leitura dos alunos e o período do curso, foram considerados nove semestres, estruturados em cinco períodos anuais. Não foi possível, 
contudo, identificar a qual ano pertencem dez respondentes da amostra, e seus resultados foram classificados no grupo "diversos".

Os resultados foram divididos em dois tópicos, contendo as duas dimensões do instrumento aplicado, conforme segue.

\subsection{Resultados das funções da leitura}

Para efeito de classificação do nível de uso das funções da leitura, a pontuação média foi parametrizada conforme está na Tabela 3:

Tabela 3

\section{Pontuação das funções da leitura}

\begin{tabular}{l|l}
\hline Nível & Pontuação média de uso da função \\
\hline Alto & De 11 a 15 pontos \\
Médio & De 6 a 10 pontos \\
Baixo & Abaixo de 5 pontos \\
\hline
\end{tabular}

Fonte: Oliveira (1996).

As funções "aprendizagem", "utilidade", "moralidade" e "estímulo", segundo escala de Greaney e Neuman (1990), valoradas pelos alunos, estão descritas por média de uso, desvio padrão e variância na Tabela 4.

Tabela 4

Uso das funções da leitura

\begin{tabular}{cllr|r|r|r|r|r|r}
\hline Funções & Critério & $\mathbf{1}^{\circ}$ Ano & $\mathbf{2}^{\circ}$ Ano & $\mathbf{3}^{\circ}$ Ano & $\mathbf{4}^{\circ}$ ano & $\mathbf{5}^{\circ}$ ano & Diversos & Geral \\
\hline \multirow{4}{*}{ Aprendizagem } & Média & 11,800 & 10,725 & 10,902 & 11,186 & 10,462 & 11,200 & 10,983 \\
& Desvio padrão & 1,642 & 2,996 & 2,663 & 2,270 & 2,370 & 2,700 & 2,516 \\
& Variância & 2,695 & 8,974 & 7,090 & 5,155 & 5,618 & 7,289 & 6,329 \\
& Média & 12,350 & 11,375 & 12,146 & 12,047 & 12,038 & 12,000 & 11,950 \\
Utilidade & Desvio padrão & 2,300 & 2,579 & 2,080 & 2,370 & 2,306 & 3,464 & 2,397 \\
& Variância & 5,292 & 6,651 & 4,328 & 5,617 & 5,318 & 12,000 & 5,746 \\
Moralidade & Média & 8,350 & 7,500 & 8,098 & 7,767 & 8,154 & 8,800 & 7,961 \\
& Desvio padrão & 3,249 & 3,359 & 3,368 & 3,702 & 3,495 & 3,824 & 3,449 \\
& Variância & 10,555 & 11,282 & 11,340 & 13,707 & 12,215 & 14,622 & 11,892 \\
& Média & 9,650 & 7,950 & 8,561 & 8,837 & 8,038 & 8,400 & 8,528 \\
& Desvio padrão & 2,907 & 3,909 & 3,782 & 3,741 & 4,015 & 4,477 & 3,774 \\
& Variância & 8,450 & 15,279 & 14,302 & 13,997 & 16,118 & 20,044 & 14,239 \\
\hline
\end{tabular}

Fonte: Dados da pesquisa (2018).

A média indicada situa os alunos do curso de Ciências Contábeis no nível alto de uso das funções da leitura apenas nas funções de aprendizagem e utilidade. Em relação às funções moralidade e estímulo, eles estão situados no nível médio de uso.

Os valores relativos à variância e ao desvio padrão das funções "moralidade" e "estímulo" demonstram o quão os resultados individuais dos alunos estão dispersos em relação à média. $\mathrm{O}$ dado é reforçado pelo cálculo do coeficiente de variação (CV), cujo resultado foi 44,25\% e $43,317 \%$ para as funções "estímulo" e "moralidade", respectivamente. Resultados acima de $30 \%$ são considerados como alta dispersão (Correia, 2003). Dessa forma, o comportamento de leitura dos alunos em relação a essas funções demonstrou-se irregular, existindo estudantes que faziam uso elevado das funções, enquanto outros pouco as utilizam. A figura 1 demonstra a utilização das funções da leitura por ano do curso e média de uso. 


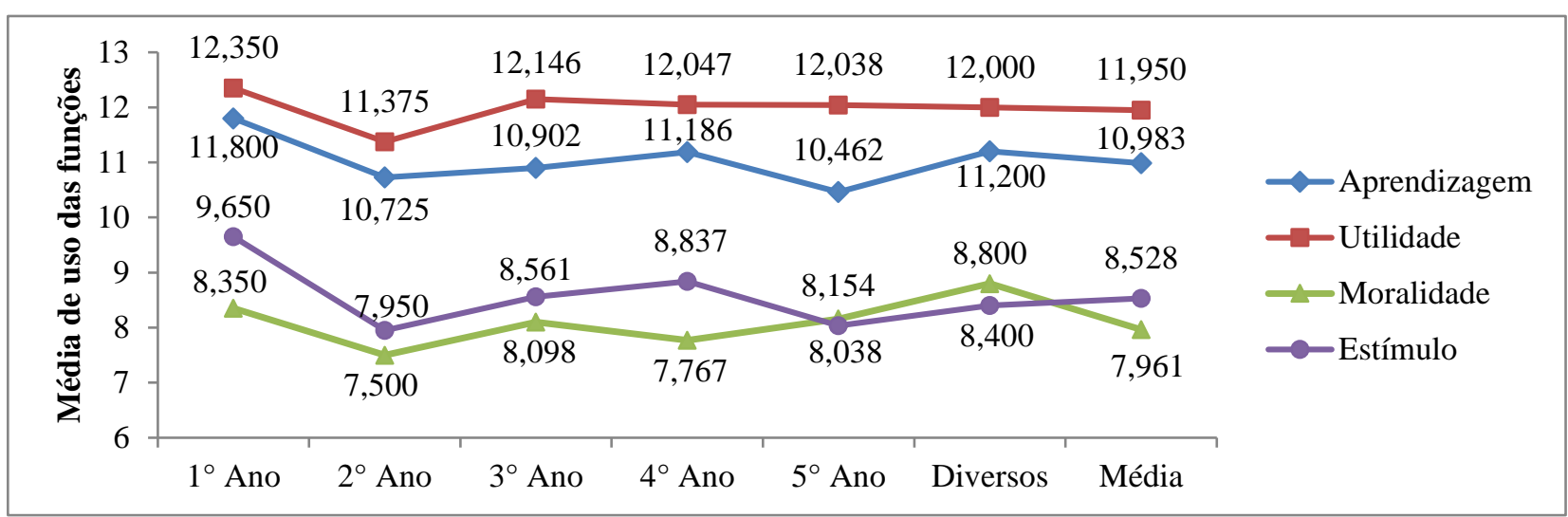

Figura 1. Média de uso das funções da leitura

Fonte: Dados da pesquisa (2018).

Os resultados corroboram estudos anteriores, nos quais as funções mais utilizadas pelos universitários foram "aprendizagem" e "utilidade". Quanto ao estímulo e à moralidade, os resultados de estudos anteriores também revelaram nível médio de utilização dessas funções (Oliveira, 1996; Centofanti et al., 1997). Conforme as conclusões desses autores, é possível que o resultado seja atribuído à fase da vida em que esses estudantes estão vivendo, que os leva a direcionar sua leitura para o aspecto aprendizagem, indispensável na vida acadêmica. Witter (1997), contudo, alerta que leituras diversificadas devem ser realizadas para abranger outros aspectos da formação de bons profissionais.

Quanto ao desenvolvimento de competências profissionais do contador, os resultados sobre o hábito de leitura dos estudantes demonstram que as competências relacionadas às funções "utilidade" e "aprendizagem" possuem um ambiente propício para que sejam desenvolvidas, na medida em que os alunos se voltam para leituras específicas da área. Sendo assim, o hábito de leitura dos estudantes consiste em uma contribuição positiva para o desenvolvimento das seguintes competências: planejamento, ferramentas de controle, contabilidade e finanças, legal, técnicas de gestão, comunicação e ouvir eficazmente (Cardoso, 2006). Entretanto, se funções da leitura ligadas à utilidade acadêmica devem ser cultivadas, as outras não podem ser deixadas de lado, sob o risco de apenar em seu desenvolvimento competências profissionais do contador relacionadas à formação ética e moral e à criatividade. Os estudantes analisados correm o risco de não adquirirem as competências "integridade e confiança", "empreendedor" e "analítica", listadas por Cardoso (2006), por apresentarem uma utilização mediana das funções "estímulo" e "moralidade".

\subsection{Resultados do teste de Cloze}

A compreensão dos alunos foi medida pelo teste de Cloze. Os resultados estão dispostos em percentual na Tabela 5 .

\section{Tabela 5}

\section{Percentual de acerto no teste de Cloze}

\begin{tabular}{l|c|c|c|c|c|c|c|c}
\hline \% Acerto & $\mathbf{1}^{\circ}$ Ano & $\mathbf{2}^{\circ}$ Ano & $\mathbf{3}^{\circ}$ Ano & $\mathbf{4}^{\circ}$ Ano & $\mathbf{5}^{\circ}$ Ano & Diversos & Geral & $\begin{array}{c}\text { Kruskal- } \\
\text { Wallis }\end{array}$ \\
\hline Médio & $51,957 \%$ & $47,880 \%$ & $45,334 \%$ & $45,147 \%$ & $51,923 \%$ & $47,391 \%$ & $47,657 \%$ & \\
Mínimo & $21,739 \%$ & $15,217 \%$ & $21,739 \%$ & $4,348 \%$ & $10,870 \%$ & $21,739 \%$ & $4,348 \%$ & 4,922 \\
Máximo & $73,913 \%$ & $76,087 \%$ & $73,913 \%$ & $84,783 \%$ & $80,435 \%$ & $60,870 \%$ & $84,783 \%$ & (significância \\
Desvio padrão & $14,944 \%$ & $15,910 \%$ & $13,103 \%$ & $17,615 \%$ & $14,332 \%$ & $11,217 \%$ & $15,249 \%$ & $0,425)$ \\
Variância & $2,233 \%$ & $2,531 \%$ & $1,717 \%$ & $3,103 \%$ & $2,054 \%$ & $1,258 \%$ & $2,325 \%$ & \\
\hline
\end{tabular}

Fonte: Dados da pesquisa (2018). 
Conforme observado da Tabela 5, a média de acertos geral foi 47,657\%. O melhor desempenho no teste de Cloze foi do primeiro ano, com acerto médio de 51,957\%, seguido pelo quinto $(51,923 \%)$. O pior desempenho foi observado no quarto ano, com acerto médio de 45,147\%, seguido pelo terceiro $(45,334 \%)$. O melhor e o pior desempenhos individuais foram observados em sujeitos do quarto ano, com percentual de acerto de $84,783 \%$ e 4,348\%. Ainda por meio da Tabela 3, depreende-se que o teste de Kruskal-Wallis $(4,922$, com significância de 0,425$)$ não foi estatisticamente significante, ou seja, a probabilidade de diferenças entre os grupos (anos cursados) estarem relacionadas ao acaso supera o nível de 10\%. Portanto, não existem diferenças significativas entre os grupos, sinalizando que para esse conjunto de dados, os anos cursados não provocam aumento na média dos pontos relacionados à compreensão leitora mensurada pelo teste de Cloze. A Figura 2 demonstra a média de acerto dos alunos.

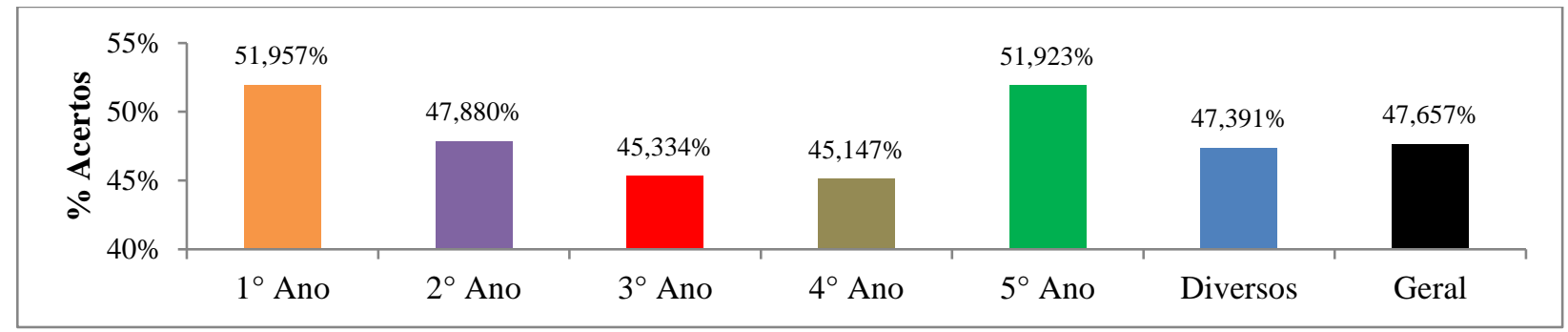

Figura 2. Média de acerto no teste de Cloze

Fonte: Dados da pesquisa (2018).

Em termos qualitativos, os alunos foram distribuídos em níveis de leitura, conforme resultados no teste de Cloze, seguindo o modelo de Bormuth (1968). A Tabela 6 demonstra a distribuição dos alunos, por percentual de acerto, nos três níveis de leitura parametrizados pelo autor.

Tabela 6

Níveis de leitura dos alunos

\begin{tabular}{ccc|c|c|c|c|c|c|c}
\hline Níveis & $\mathbf{1}^{\circ}$ Ano & $\mathbf{2}^{\circ}$ Ano & $\mathbf{3}^{\circ}$ Ano & $\mathbf{4}^{\circ}$ Ano & $\mathbf{5}^{\circ}$ Ano & Diversos & Total & \% \\
\hline Frustração (até 44\%) & 5 & 15 & 20 & 21 & 5 & 3 & 69 & $38 \%$ \\
Instrucional (de 44, 1\% a 57\%) & 6 & 12 & 15 & 13 & 11 & 6 & 63 & $35 \%$ \\
Independente (acima de 57\%) & 9 & 13 & 6 & 9 & 10 & 1 & 48 & $27 \%$ \\
Total & 20 & 40 & 41 & 43 & 26 & 10 & 180 & $100 \%$ \\
\hline
\end{tabular}

Fonte: Dados da pesquisa (2018).

A maior parte dos respondentes encontra-se no nível de frustração (38\%), ou seja, denotam dificuldades graves na compreensão da leitura e não conseguem abstrair de forma satisfatória a informação lida. O número de alunos que se encontram no nível instrucional, porém, é aproximado (35\%), sinalizando que conseguem compreender de forma suficiente o assunto lido, no entanto, não expressam comportamento criativo, flexível, autônomo e fluente. Já no nível independente de leitura encontram-se $27 \%$ dos alunos, com uma boa compreensão textual. Outras pesquisas da área obtiveram resultados semelhantes no teste de Cloze em universitários, demonstrando um baixo nível de compreensão de leitura, que se reflete no desempenho acadêmico dos estudantes (Centofanti et al., 1997; Freitag et al., 2014; Oliveira \& Oliveira, 2007; Santos et al., 2004). Relacionando os resultados obtidos ao desenvolvimento de competências profissionais do contador, percebe-se que a baixa compreensão dos alunos prejudica a prática da leitura eficiente e eficaz. Sendo assim, o ambiente gerado pelo hábito de leitura dos universitários para aquisição de competências é prejudicado. Esses dados são alarmantes, visto que que se tratam de universitários 
que em breve ingressarão no mercado de trabalho e, se não houver programas interventivos com intuito de ajustar a situação, presumivelmente sairão com uma qualificação técnica insuficiente para os desafios inerentes à profissão.

\section{CONCLUSÕES}

Os dados das figuras e tabelas demonstram que as funções da leitura "aprendizagem" e "utilidade" são muito utilizadas pelos estudantes, mas seu uso pode ser ampliado para chegar ao grau máximo de utilização. Com esse resultado, pode-se afirmar que os alunos detêm grandes chances de desenvolver as competências do contador relacionadas à aquisição de conhecimentos e aprimoramento da linguagem ao final do curso superior, quando concluírem sua formação profissional e se inserirem no mercado de trabalho, na medida em que a leitura com essa função consiste em um ambiente favorável ao desenvolvimento dessas habilidades. Assim, é notória a importância do cultivo e incentivo do hábito de leitura, relacionado ao aprendizado e à utilidade, nos universitários.

Por sua vez, as funções "estímulo" e "moralidade" demonstraram um nível médio de utilização. Sendo assim, as competências relacionadas à ética e à criatividade não encontraram um ambiente completamente favorável para que sejam adquiridas por via do hábito de leitura dos estudantes. A importância da leitura de outros textos que não os técnicos ligados à área de atuação foi ressaltada por autores como Centofanti et al. (1997), que aconselharam diversificar o material lido, despertando o interesse do aluno pela leitura.

No concernente à compreensão textual auferida no teste de Cloze, os resultados demonstram que a maior parte dos leitores se encontra em níveis de frustração e dependência, por possuírem pouca compreensão em leitura, o que a torna ineficiente e ineficaz para as finalidades pretendidas pelo aluno leitor. Dessa forma, esse problema reflete negativamente para o desenvolvimento de competências por meio da leitura, pois esta deve ser realizada em pleno entendimento do texto lido, para que o seu conteúdo seja satisfatoriamente absorvido.

O desempenho dos alunos não demonstrou ter recebido influência da universidade. Era esperada uma evolução no nível de leitura, atribuída à maturidade alcançada no decorrer do curso, porém não foi o que ocorreu. Alunos do primeiro ano obtiveram melhor desempenho do que os do penúltimo.

O estudo atingiu os objetivos a que se propôs, contudo é importante que se considerem as limitações desta pesquisa, em especial, no que concerne a sua restrição a uma só instituição. Sugere-se que este estudo seja estendido a outras instituições de ensino para que se possa fazer um comparativo no nível de leitura do estudante de instituições públicas e privadas. Outra limitação da pesquisa é a de que os respondentes não foram acompanhados no decorrer do curso, para testar sua evolução em leitura. Uma sugestão é a aplicação para os mesmos alunos nos seus distintos anos de formação, permitindo inferir sobre a contribuição da universidade para o aprimoramento do hábito da leitura por meio do acompanhamento dessa evolução.

Sugere-se ainda uma investigação sobre as ações que a universidade toma para desenvolver o uso das funções da leitura e a melhora da compreensão textual nos seus alunos, com vistas a identificar que mecanismo pode ser utilizado para solucionar os problemas apontados. Como contribuição prática, recomenda-se o aprimoramento da prática da leitura no meio acadêmico, para que os futuros profissionais detenham as competências requeridas pelo mercado de trabalho e, consequentemente, obtenham o sucesso profissional pretendido ao término do curso. 


\section{REFERÊNCIAS}

Abdolmohammadi, M. J., Searfoss, D. G., \& Shanteau, J. (2004). An investigation of the attributes of top industry audit specialists. Behavioral Research in Accounting, 16(1), 1-17.

Alves, S. V. (2005). Trabalhando as inteligências múltiplas em sala de aula. Brasília: Plano.

American Institute of Certified Public Accountants. Core competency framework for entry into the accounting professions. New York: American Institute of Certified Public Accountants, 1999.

Arrigucci, D., Jr. (1994). Leitura: entre o fascínio e o pensamento. Série Idéias, (13), 19-24.

Beck, F., \& Rausch, R. B. (2015). Fatores que influenciam o processo ensino-aprendizagem na percepção de discentes do curso de ciências contábeis. Contabilidade Vista \& Revista,25(2), $38-58$.

Bormuth, J. R. (1968). Cloze test readability: Criterion reference scores. Journal of educational measurement, 5(3), 189-196.

Bower, J. B. (1957). A Profession of Accounting-or of Accountancy? The Accounting Review, 32(2), 194.

Boyatzis, R. E., Stubbs, E. C., \& Taylor, S. N. (2002). Learning cognitive and emotional intelligence competencies through graduate management education. Academy of Management Learning \& Education, 1(2), 150-162.

Brito, D. S. (2010). A importância da leitura na formação social do indivíduo. Periódico de Divulgação Científica da FALS, 4(8), 1-35.

Cardoso, J. L., de Souza, M. A., \& Almeida, L. B. (2006). The accountant's profile in the present: an exploratory study.BASE: Revista de Administração e Contabilidade da Unisinos,3(3), 275-284.

Cardoso, R. L. (2006). Competências do contador: um estudo empírico. Tese de Doutorado, Faculdade de Economia, Administração e Contabilidade, Universidade de São Paulo, São Paulo, SP, Brasil. Recuperado de http://www.teses.usp.br/teses/disponiveis/12/12136/tde03042007-100732/

Cardoso, R. L., \& Riccio, E. L. (2010). Existem competências a serem priorizadas no desenvolvimento do contador? Um estudo sobre os contadores brasileiros. REGE Revista de Gestão, 17(3), 353-367.

Centofanti, E. M., Ferreira, S. M., \& Del Tedesco, T. (1997). Compreensão da leitura por universitários de psicologia. In G. P. Witter (Org.). Leitura e universidade (pp. 33-60). Campinas: Alínea.

Chaguri, A., Barbosa, B. A., Arouca, E. A., \& Wuo, M. (1997). Compreensão de leitura: estudo comparativo entre universitários. Psicologia leitura \& universidade, 61-76. 
Conselho Federal de Contabilidade (1996). Resolução CFC $n^{o}$. 803, de 10 de outubro de 1996. Aprova o Código de Ética Profissional do Contador - CEPC. Brasília: Autor. Recuperado de: http://www2.cfc.org.br/sisweb/sre/detalhes_sre.aspx?Codigo=1996/000803

Correia, M. S. B. B. (2003). Probabilidade e estatística (2a ed.). Belo Horizonte: PUC Minas Virtual.

Cunha, N. B., \& Santos, A. A. A. dos (2006). Relação entre a compreensão da leitura e a produção escrita em universitários. Psicologia: Reflexão e Crítica, 19(2), 237-245.

Fleury, M. T. L., \& Fleury, A. (2001). Construindo o conceito de competência. Revista de Administração Contemporânea, 5(Edição Especial), 183-196.

Francis, M. C., Mulder, T. C., \& Stark, J. S. (1995). Intentional learning: a process for learning to learn in the accounting curriculum. Sarasota, FL: Accounting Education, Change Comission and American Accounting Association, 1995. Accounting Education Series, 12.

Freire, P. (2017). A importância do ato de ler em três artigos que se completam. São Paulo: Cortez.

Freitag, R. M. K., Sarmento, V. H. V., Costa, C. C., \& Santos, K. L. (2015). Teste cloze e a competência em leitura de universitários: uma experiência no curso química/licenciatura da UFS/Itabaiana. InterSciencePlace, 1(30), 1-13.

Gil, A. C. (2010). Como elaborar projetos de pesquisa (5a ed.). São Paulo: Atlas.

Gil, A. C. (2012). Métodos e técnicas de pesquisa social (6a ed.) São Paulo: Atlas.

Greaney, V., \& Neuman, S. B. (1990). The functions of reading: a cross-cultural perspective. Reading Research Quarterly, 25(3), 172-195.

Hardern, G. (1995). The development of standards of competence in accounting. Accounting Education, 4(1), 17-27.

Henning, D. A., \& Moseley, R. L. (1970). Authority role of a functional manager: the controller. Administrative science quarterly, 482-489.

Henry, L. J. (1995). Persistence leads to accounting performance: How to spot a persistent potential employee. Arkansas Business and Economic Review, 28(3), 1-6.

International Federation of Accountants' Education Committee. Towards competent professional accountants. New York: IFAC, 2003.

Kester, R (1928). The importance of the controller. The Accounting Review, 3(3), 237-251.

Martins, G. D. A., \& Theóphilo, C. R. (2009). Metodologia da pesquisa científica para ciências sociais aplicadas. São Paulo: Atlas.

Masetto, M. T. (2003). Competência pedagógica do professor universitário (Cap. 2, pp. 19-33). São Paulo: Summus. 
McClelland, D. C. (1973). Testing for competence rather than for "intelligence". American psychologist, 28(1), 1-14.

Mohamed, E. K., \& Lashine, S. H. (2003). Accounting knowledge and skills and the challenges of a global business environment. Managerial finance, 29(7), 3-16.

Morgan, G. J. (1997). Communication skills required by accounting graduates: practitioner and academic perceptions. Accounting Education, 6(2), 93-107.

Needles, B. E., Jr, Cascini, K., Krylova, T., \& Moustafa, M. (2001). Strategy for Implementation of IFAC International Education Guideline No. 9: "Prequalification Education, Tests of Professional Competence and Practical Experience of Professional Accountants": A Task Force Report of the International Association for Accounting Education and Research (IAAER). Journal of International Financial Management \& Accounting, 12(3), 317-353.

Oliveira, M. H. M. A. D. (1996). Funções da leitura para estudantes de graduação. Psicologia Escolar e Educacional, 1(1), 61-68.

Oliveira, R. Á. M. D., \& Oliveira, K. L. D. (2007). Leitura e condições de estudo em universitários ingressantes. Psic: revista da Vetor Editora, 8(1), 51-59.

Pinto, C. J. A., Alvarenga, M. A. P., \& Kock, R. A. A. (1997). Hábito de leitura e compreensão de texto entre universitários. In G. P. Witter (Org.). Psicologia: leitura e universidade (pp. 3360). Campinas: Alínea.

Pires, E. D. N. (2012). A importância do hábito da leitura na universidade. Revista ABC: Biblioteconomia em Santa Catarina, 17(2), 365-381.

Ramirez, P. (2003). Uma estratégia para melhoria da formação de competências para o profissional de nível técnico na área de gestão. Dissertação de Mestrado, Centro Universitário Nove de Julho, São Paulo, SP, Brasil.

Raupp, F. M., \& Beuren, I. M. (2006). Metodologia da Pesquisa Aplicável às Ciências. In I. M. Beuren (Org.). Como elaborar trabalhos monográficos em contabilidade: teoria e prática (Cap. 3, pp. 76-97). São Paulo: Atlas.

Ribeiro, J. U. (2011). Um brasileiro em Berlim. Rio de Janeiro: Nova Fronteira.

Richardson, R. J. (2012). Pesquisa social: métodos e técnicas (3a ed.). São Paulo: Atlas.

Santos, A. A. A., Primi, R., de O. S., Taxa, F., \& Vendramini, C. M. (2002). O teste de Cloze na avaliação da compreensão em leitura. Psicologia: reflexão e crítica, 15(3), 549-560.

Santos, A. A., Suehiro, A. C., \& Oliveira, K. L. D. (2004). Habilidades em compreensão da leitura: um estudo com alunos de psicologia. Estudos de Psicologia, 21(2), 29-41.

Siegel, G., \& Sorensen, J. E. (1999). Counting more, counting less. Transformations in the management accounting profession. Institute of Management Accountants. 
Silva, E. T. da (1992). O ato de ler: fundamentos psicológicos para uma nova pedagogia da literatura. São Paulo: Cortez.

Spencer, L. M., \& Spencer, S. M. (1993). Competence at Work. New York: Johwn Wiley \& Sons.

Taylor, W. L. (1953). “Cloze procedure": a new tool for measuring readability. Journalism Bulletin, 30(4), 415-433.

Tourinho, C. (2012). Refletindo sobre a dificuldade de leitura em alunos do ensino superior: "deficiência" ou simples falta de hábito? Revista Lugares de Educação, 1(2), 325-346.

Valentim, M. L. P. (2008). Criatividade e inovação na atuação profissional. CRB-8 Digital, 1(1), 3-9.

Witter, G. P. (1996). Avaliação da produção científica sobre leitura na universidade (1989/1994). Psicologia Escolar e Educacional, 1(1), 31-37.

Witter, G. P. (1997). Leitura e universidade. In G. P. Witter (org.). Psicologia: leitura e universidade (pp. 9-18). Campinas: Alínea. 